\title{
Benzofuran synthesis through iodocyclization reactions: recent advances
}

\section{Abstract}

Recent advancements (2014-17) in the benzofuran synthesis through iodocyclization have been summarized. The successful use of various iodinating agents, bases, additives etc. make iodocyclization a versatile and efficient methodology. The methodology has been applied for the synthesis of more complex benzofuran derivatives, and may open interesting avenues in the area of heterocyclic chemistry (Figure 1).

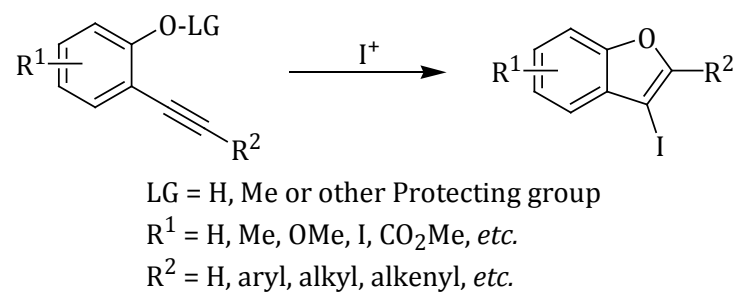

Figure I

Keywords: annulations, alkyne, benzofuran, iodocyclization, heterocycle
Volume I Issue 7 - 2017

\section{Saurabh Mehta}

Department of Applied Chemistry, Delhi Technological

University, India

\begin{abstract}
Correspondence: Saurabh Mehta, Department of Applied Chemistry, Delhi Technological University, Bawana Road, Delhi, I 10042 India, Tel +9| 8800665868 ,
\end{abstract}

Email saurabh.mehta@dtu.ac.in, saurabh.dtu@gmail.com

Received: December 17, 2017 | Published: December 29, 2017

\section{Introduction}

Benzo $[b]$ furan is a privileged heterocyclic scaffold. Several compounds containing this scaffold have interesting biological activities, such as anti-cancer, anti-viral, anti-inflammatory, etc. ${ }^{1}$ Few derivatives are even used as commercial drugs, such as Amiodarone, ${ }^{2}$ or investigational drugs, such as Bufuralol, ${ }^{3}$ etc. (Figure 2).<smiles>CCCCc1oc2ccccc2c1C(=O)c1cc(I)c(OCCN(CC)CC)c(I)c1</smiles>

Amiodarone (Antiarrhythmic agent)

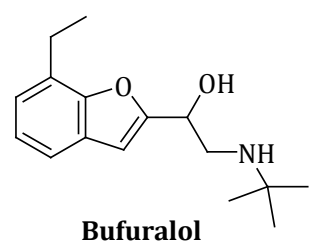

(ß-Adrenergic blocker)
Figure 2 Examples of Benzo[b]furan scaffold containing drugs.

Over the years many synthetic routes have been reported for the preparation of benzofurans. . $^{1,45}$ Iodocyclization of functionalized alkynes is one of the most important and efficient synthetic methodologies for the synthesis of important heterocyclic compounds, including benzofurans. ${ }^{6,7}$ Due to our continuous interest in the synthesis and biological evaluation of important heterocycles, ${ }^{8-10}$ we became interested in Benzofuran synthesis. Here the recent advances (2014-17) in this powerful strategy for making benzofurans are reported.

\section{Discussion}

Okitsu et al. ${ }^{11}$ recently reported a versatile synthesis of benzo[b] furans through iodocyclization of the ethoxyethyl ether-substituted alkynes (Scheme 1). ${ }^{11}$ The reactions get completed within three seconds at room temperature and the corresponding benzofuran derivatives were obtained in high yields $(84 \%-100 \%)$ under mild conditions. The authors demonstrated that the choice of bis $(2,4,6-$ collidine)iodonium hexafluorophosphate $\left[\mathrm{I}(\mathrm{coll})_{2} \mathrm{PF}_{6}\right]$ as the iodinating agent was necessary for the success of the reaction. Also, the ethoxyethyl ether group acted as a protecting group as well as a good leaving group.

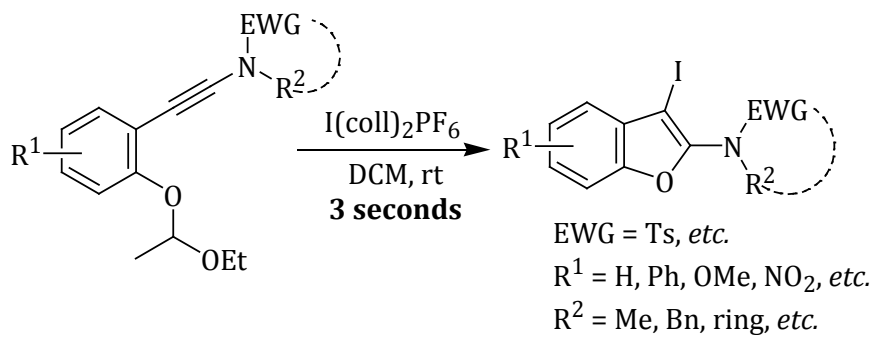

\section{Scheme I}

The authors used a similar and previously reported methodology ${ }^{12}$ for the synthesis (Scheme 2) of an antiarrhythmic agent Dronedarone (marketed as Multaq ${ }^{\circledR}$ from Sanofi-Aventis). ${ }^{13}$

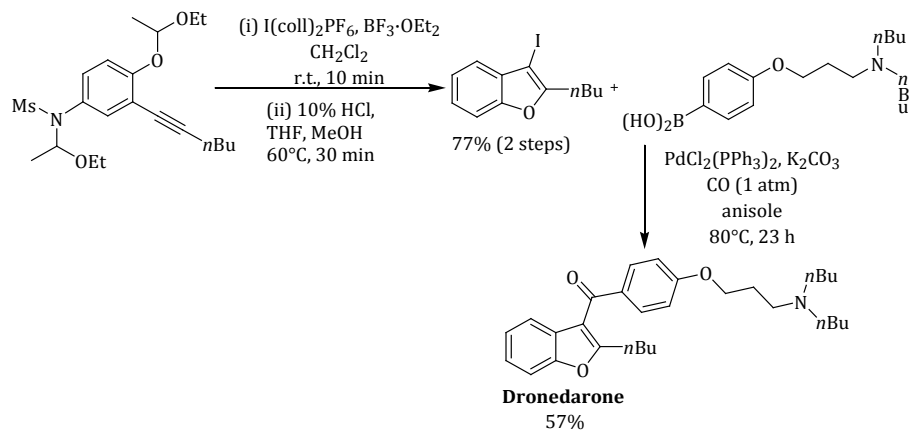

Scheme 2 
Wang et al. ${ }^{14}$ developed a novel and straightforward way for the preparation of 3-trifluoromethylbenzofurans. ${ }^{14}$ The methodology involves a two-step, one-pot tandem iodocyclization and trifluoromethylation reaction and affords the 3 -trifluoromethylbenzofurans in moderate to excellent yields (Scheme $3)$.<smiles>[R1]c1ccccc1C#Cc1cc[R](C)cc1</smiles>

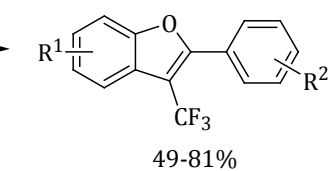

$\mathrm{R}^{1}=\mathrm{H}, \mathrm{Cl}, \mathrm{F}, \mathrm{OMe}, \mathrm{Ph}$, alkyl, etc. $\mathrm{R}^{2}=\mathrm{H}, \mathrm{Cl}, \mathrm{F}, \mathrm{OMe}$, alkyl, $\mathrm{CO}_{2} \mathrm{Me}, \mathrm{CN}$, etc.

\section{Scheme 3}

Danilkina et al..$^{15}$ reported an efficient strategy for the synthesis of asymmetrically substituted enediynes fused to benzofuran, and other important heterocycles (Scheme 4). ${ }^{15}$ The authors also demonstrated the extension of the methodology for the synthesis of fused macrocycles of indole derivatives.

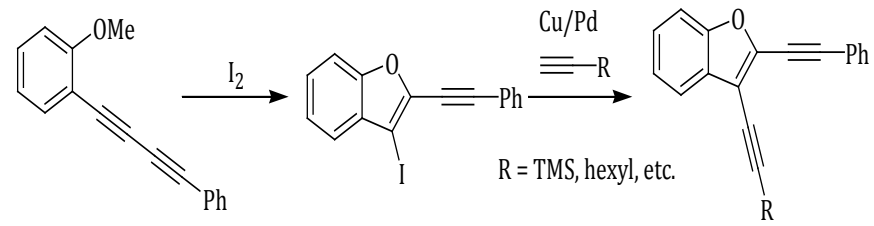

\section{Scheme 4}

Li et al. ${ }^{16}$ demonstrated that a variety of 3 -iodobenzo $[b]$ furan derivatives can be conveniently prepared from the corresponding 2-alkynylphenols through $\mathrm{Ph}_{3} \mathrm{P}$-catalyzed iodocyclization in the presence of $\mathrm{N}$-iodosuccinimide (NIS) ${ }^{16}$ This protocol provides a quick access to and 3-iodobenzo[ $b]$ furans in good to excellent yields under mild conditions (Scheme 5).

$$
\begin{array}{ll}
\mathrm{R}^{1}=\mathrm{H}, \mathrm{Br} \\
\mathrm{R}^{2}=\text { alkyl, aryl }
\end{array}
$$

\section{Scheme 5}

Using the iodocyclization methodology (Scheme 6). ${ }^{17,18} \mathrm{He}$ et al. ${ }^{19}$ designed and synthesized a 45-compound library of multi-substituted benzofurans, and using a high-throughput, cell-based HCV luciferase reporter assay studied its anti-hepatitis $\mathrm{C}$ virus (HCV) activity. ${ }^{19}$ The optimization of the scaffold resulted in the identification of several potent inhibitors $\left(\mathrm{EC}_{50}<100 \mathrm{nM}\right)$ of $\mathrm{HCV}$ with low cytotoxicity $\left(\mathrm{CC}_{50}>25 \mu \mathrm{M}\right)$, and good selectivity (selectivity index $=\mathrm{CC}_{50} / \mathrm{EC}_{50}$, $>371$-fold).

Jung et al. ${ }^{20}$ recently reported an efficient synthetic approach to polysubstituted benzofurans where 2-methoxyquinone was used as a benzofuran backbone. The starting quinols were reduced to the phenols, the-OH group was protected and these substrates were further subjected to iodocyclization conditions affording the corresponding benzofurans (Scheme 7). ${ }^{20}$

Raminelli et al. ${ }^{21}$ recently reported an interesting methodology for synthesizing diiodo-functionalized benzo $[b]$ furans..$^{21}$ The reaction involves the iodocyclization of alkynylated 2-iodoanisoles using $\mathrm{I}_{2}$ in the presence of sodium bicarbonate as base (Scheme 8). The resulting products containing two C-I bonds offer opportunities for further diversification of this important scaffold.

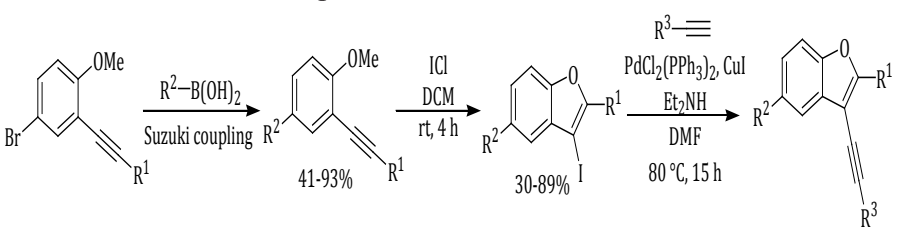

\section{Scheme 6}

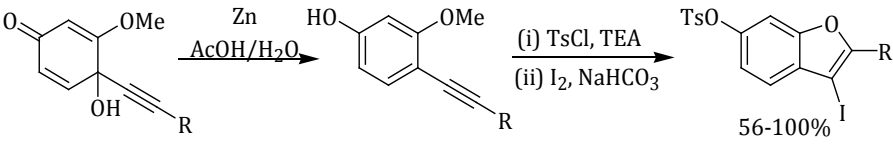

$\mathrm{R}=$ alkyl, aryl, alkenyl, etc.

Scheme 7<smiles>[R]C#Cc1cc([R])cc(I)c1OC</smiles><smiles>[R]c1cc(I)c2oc([R])c(I)c2c1</smiles>

$45-99 \%$

\section{Scheme 8}

\section{Conclusion}

Thus, the iodocyclization strategy presents an efficient approach for the synthesis of diverse benzo $[b]$ furan derivatives. The choice of reagents, fast and high yielding reactions combined with the functional group tolerance make it a strategy of choice for many heterocyclic chemists. Further advances in this area of research are expected.

\section{Acknowledgements}

The author thanks Delhi Technological University for the resources provided for the completion of this work.

\section{Conflict of interest}

The author declares no conflict of interest.

\section{References}

1. Khanam H, Shamsuzzaman. Bioactive Benzofuran Derivatives: A Review. Eur J Med Chem. 2015;97:483-504.

2. Siddoway LA. Amiodarone: Guidelines for Use and Monitoring. $A m$ Fam Physician. 2003;68(11):2189-2196.

3. Narimatsu S, Takemi C, Kuramoto S, et al. Stereoselectivity in the Oxidation of Bufuralol, a Chiral Substrate, by Human Cytochrome P450s. Chirality. 2003;15(4):333-339.

4. Abu-Hashem AA, Hussein HAR, Aly AS, et al. Synthesis of Benzofuran Derivatives via Different Methods. Synth Commun. 2014;44(16):22852312

5. Wu XF, Li Y. Transition Metal-Catalyzed Benzofuran Synthesis. Netherlands: Elsevier; 2017. p. 1-71.

6. Godoi B, Schumacher RF, Zeni G. Synthesis of Heterocycles via Electrophilic Cyclization of Alkynes Containing Heteroatom. Chem Rev. 2011;111(4):2937-2980. 
7. Gabriele B, Mancuso R, Larock RC. Recent Advances in the Synthesis of Iodoheterocycles via Iodocyclization of Functionalized Alkynes. Curr Org Chem. 2014;18(3):341-358.

8. Mehta S, Waldo JP, Larock RC. Competition Studies in Alkyne Electrophilic Cyclization Reactions. J Org Chem. 2009;74(3):1141-1147.

9. Mehta S, Waldo JP, Neuenswander B, et al. Solution-Phase Parallel Synthesis of a Multisubstituted Cyclic Imidate Library. ACS Comb Sci. 2013;15(5):247-254.

10. Huang Q, Rui EY, Cobbs M, et. al. Design, Synthesis, and Evaluation of NO-Donor Containing Carbonic Anhydrase Inhibitors to Lower Intraocular Pressure. J Med Chem. 2015;58(6):2821-2833.

11. Okitsu T, Nakata K, Nishigaki K, et al. Iodocyclization of Ethoxyethyl Ethers to Ynamides: An Immediate Construction to Benzo[b]furans. $J$ Org Chem. 2014;79(12):5914-5920.

12. Okitsu T, Nakazawa D, Taniguchi R, et al. Iodocyclization of Ethoxyethyl Ethers to Alkynes: A Broadly Applicable Synthesis of 3-Iodobenzo[b]furans. Org Lett. 2008;10(21):4967-4970.

13. Okitsu T, Ogasahara M, Wada A. Convergent Synthesis of Dronedarone, an Antiarrhythmic Agent. Chem Pharm Bull (Tokyo). 2016;64(8):1149 1153.

14. Wang WY, Hu BL, Deng CL, et al. One-Pot Synthesis of 3-Trifluoromethylbenzofurans via Tandem Iodocyclization and Trifluoromethylation of 2-Alkynylanisoles. Tet Lett. 2014;55(8):1501-1503.
15. Danilkina NA, Kulyashova AE, Khlebnikov AF, et al. Electrophilic Cyclization of Aryldiacetylenes in the Synthesis of Functionalized Enediynes Fused to a Heterocyclic Core. J Org Chem. 2014;79(19):9018-9045.

16. Li YL, Li J, Yu SN, et al. A Concise Approach for the Synthesis of 3-Iodoindoles and 3-Iodobenzo[b]furans via $\mathrm{Ph}_{3} \mathrm{P}-$ Catalyzed Iodocyclization. Tetrahedron. 2015;71(43):8271-8277.

17. Yue D, Yao T, Larock RC. Synthesis of 2,3-Disubstituted Benzo[b] furans by the Palladium-Catalyzed Coupling of O-Iodoanisoles and Terminal Alkynes, Followed by Electrophilic Cyclization. J Org Chem. 2005;70(25):10292-10296.

18. Cho $\mathrm{CH}$, Neuenswander B, Lushington GH, et al. Parallel Synthesis of a Multi-Substituted Benzo[b]furan Library. J Comb Chem. 2008;10(6):941-947.

19. He S, Jain P, Lin B, et. al. High-Throughput Screening, Discovery, and Optimization to Develop a Benzofuran Class of Hepatitis C Virus Inhibitors. ACS Comb Sci. 2015;17(10):641-652.

20. Jung Y, Kim I. Chemoselective Reduction of Quinols as an Alternative to Sonogashira Coupling:Synthesis of Polysubstituted Benzofurans. Org Biomol Chem. 2016;14(44):10454-10472.

21. Frota C, Rossini AFC, Casagrande GA, et al. Synthesis of Diiodo-Functionalized Benzo[b]furans via Electrophilic Iodocyclization. J Braz Chem Soc. 2017;28(10):2038-2044. 